\title{
Fourier-transform infrared spectroscopic characterization of natu- rally occurring glassy fulgurites
}

\author{
B J SAIKIA ${ }^{\dagger}$, G PARTHASARATHY*, N C SARMAH ${ }^{\dagger}$ and G D BARUAH ${ }^{\dagger}$ \\ National Geophysical Research Institute, Uppal Road, Hyderabad 500 007, India \\ ${ }^{\dagger}$ Department of Physics, Dibrugarh University, Dibrugarh 786 004, India
}

MS received 7 August 2007

\begin{abstract}
We report here for the first time the spectroscopic characterization of natural fulgurites of Garuamukh. On April 22, 2005 at $04: 00$ local time, large amounts of black-brown colour of colloidal solution came out from below the earth's surface at Garuamukh near Nagaon town (latitude $26^{\circ} 20^{\prime} 39^{\prime \prime} \mathrm{N}$, longitude 92 ${ }^{\circ} 1^{\prime} 39^{\prime \prime} \mathrm{E}$, Assam, India) with fire and smoke. This colloidal solution got transformed into fulgurites, glassy material, within a few hours. We present here the characterization of the fulgurites by Fourier transform infrared (FTIR) absorption, X-ray diffraction and X-ray fluorescence methods. The amorphous nature of the substance has been confirmed by Fourier transform infrared spectra of the fulgurites, which exhibit prominent absorption band in the region $400-1200 \mathrm{~cm}^{-1}$, the basic component of amorphous silica. The present study might have significant implications in understanding the thermodynamic properties of naturally occurring glasses, which are formed by shock metamorphism.
\end{abstract}

Keywords. Glasses; infrared spectroscopy; fulgurites.

\section{Introduction}

Natural glass on Earth occurs due to either meteorites impact or lightning strike. The glass formed as a result of the collision of a meteorite with the Earth's surface is called meteoritic glass or tektite (Carron and Lowman 1961; Essen and Fisher 1986). Glass (a glassy object, to be exact) that is made as a result of a cloud-to-ground lightning discharge is called a fulgurite, from the Latin word 'fulgur' which means lightning. It is worth noting that lechatelierite (natural silica glass) is not present in obsidian, a glass-like material associated with volcanic activity. On the other hand, lightning strikes on sandy soil may produce fulgurites (Yavuz and Can 1999). Such a silicabased natural glass has also been produced at the nuclear explosion sites. The mineralogical composition (lechatelirite, cristobalite, chalcedony, opal) of fulgurites is related to the palaeo-environmental conditions of the semi-arid regions and to the melting conditions during the fulgurite forming lightning strike to the ground (Sponholz 2004). Fulgurites are also very resistant to weathering and hence the study of properties of fulgurites may be helpful in understanding the ultra-high temperature natural phenomena during lightning (Clocchiatti 1990).

There are two major types of fulgurites: sand fulgurites and rock fulgurites. Sand fulgurites are usually hollow,

*Author for correspondence (gpsarathy@ngri.res.in) glass-lined tubes with sand adhering to the outside. Rock fulgurites are formed when lightning strikes the bare surface of rocks. Rock fulgurites are relatively low in silica and exhibit a wide variety of colours, depending on the composition of the host rock. Each cloud-to-ground lightning involves energy of about $10^{9}-10^{10}$ Joules. The peak temperature of lightning channel is in the order of $30,000 \mathrm{~K}$, which is five times higher than the surface temperature of the Sun. The process of lightning strike in rock and sand is chemically similar to the micrometeorite impacts (Sheffer et al 2006). In both cases there is a rapid rise of temperature followed by a rapid cooling. The peak temperature of lightning is in between 1900 and $2300 \mathrm{~K}$ depending on moisture content, which is higher than the melting point of silica. Since all rocks and soil contain silica, so at this high temperature silica melts and passes through a relatively rapid cooling which causes the glass to solidify. Jayakaran (1998) reported the occurrence of fulgurites in Udhiyur, Tamil Nadu, in a short note. However, there are no previous reports on any physical properties studies on Indian fulgurites.

On April 22, 2005 at 04 :00 local time, large amounts of black-brown fulgurites were formed at Garuamukh near Nagaon town (latitude $26^{\circ} 20^{\prime} 39^{\prime \prime} \mathrm{N}$, longitude $92^{\circ} 41^{\prime} 39^{\prime \prime} \mathrm{E}$, Assam, India). The melt formed on the earth's surface with fire and foul odour smoke and the upper part of it gradually solidified. The solid material has been found to have a temperature of about $350 \mathrm{~K}$ even after a lapse of two days after occurrence of the event whereas the room 
Table 1. Comparison of chemical compositions of the Garuamukh fulgurites with other fulgurites.

\begin{tabular}{|c|c|c|c|c|c|c|c|}
\hline & Garuamukh (G-01) & Garuamukh (G-02) & Garuamukh (G-03) & Germany & New Jersey & Illinois & Holland \\
\hline $\mathrm{SiO}_{2}$ & $97 \cdot 5$ & $96 \cdot 8$ & $97 \cdot 2$ & $93 \cdot 8$ & $99 \cdot 0$ & $91 \cdot 66$ & $90 \cdot 2$ \\
\hline $\mathrm{Fe}_{2} \mathrm{O}_{3}$ & $0 \cdot 6$ & $0 \cdot 8$ & $0 \cdot 7$ & - & $0 \cdot 3$ & - & $0 \cdot 7$ \\
\hline $\mathrm{Al}_{2} \mathrm{O}_{3}$ & $1 \cdot 4$ & $2 \cdot 0$ & $1 \cdot 6$ & $3 \cdot 8$ & $0 \cdot 7$ & $6 \cdot 69$ & $0 \cdot 9$ \\
\hline $\mathrm{TiO}_{2}$ & $0 \cdot 5$ & $0 \cdot 3$ & $0 \cdot 6$ & - & - & - & - \\
\hline $\mathrm{CaO}$ & - & - & - & $0 \cdot 6$ & - & $0 \cdot 38$ & $0 \cdot 1$ \\
\hline $\mathrm{MgO}$ & - & - & - & - & - & $0 \cdot 12$ & $0 \cdot 5$ \\
\hline $\mathrm{Na}_{2} \mathrm{O}$ & - & - & - & - & - & 0.77 & $0 \cdot 6$ \\
\hline $\mathrm{K}_{2} \mathrm{O}$ & - & - & - & - & - & 0.73 & $0 \cdot 5$ \\
\hline
\end{tabular}

Note: The data for Germany, New Jersey, Illinois and Holland are taken from Frondel (1962).

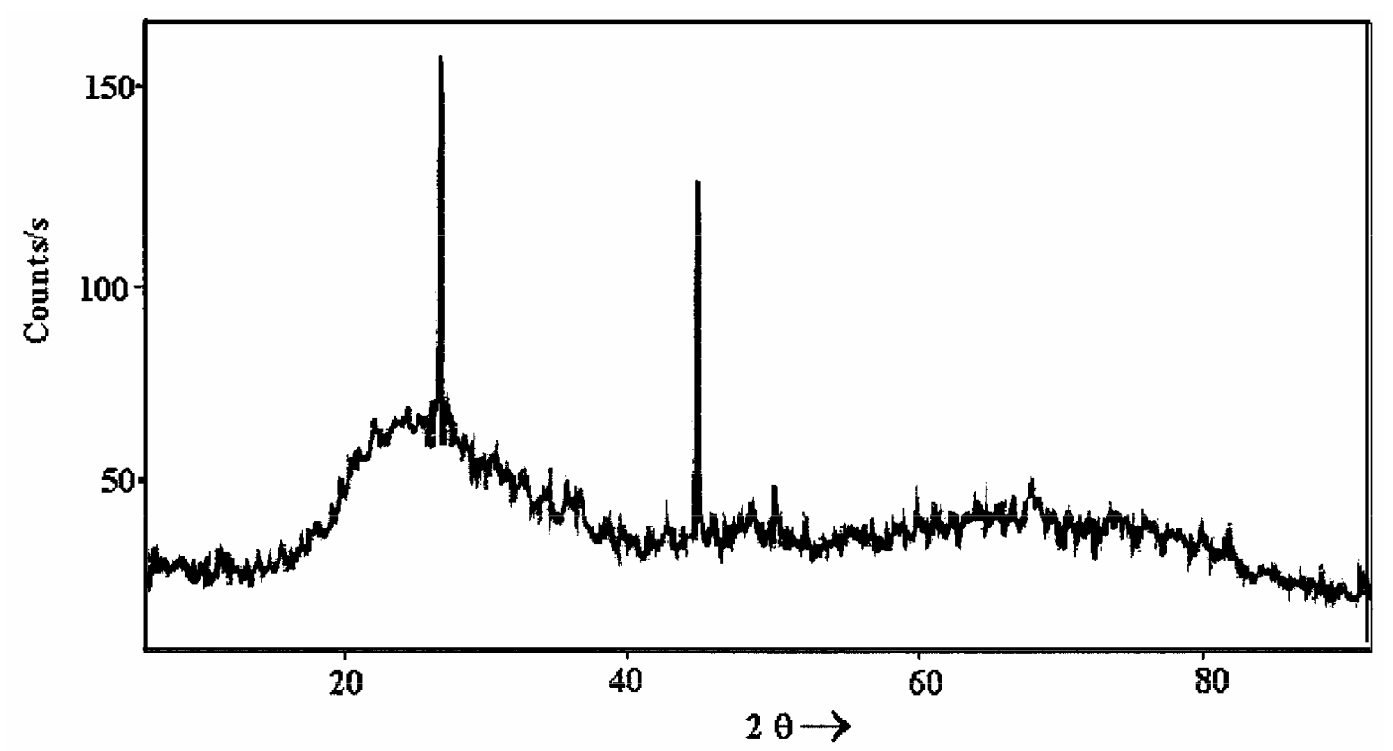

Figure 1. X-ray diffraction pattern of the Garuamukh fulgurites sample.

temperature during that period was $300 \pm 5 \mathrm{~K}$. The aim of this study is to analyse FTIR spectra of the sample with reference to $10 \mu \mathrm{m}$ and $20 \mu \mathrm{m}$ bands, because these absorption bands at middle infrared wavelengths detected the valence vibrations or deformation vibration of $\mathrm{SiO}_{4}$ tetrahedrons in silicate. The spectral characteristics of the fulgurites would be helpful in determining the peak shock temperature by identifying high-temperature phase of silica. The present study describes, for the first time, the FT-IR spectroscopic characterization of the fulgurites found at Garuamukh.

\section{Experimental}

The glassy nature of the samples were confirmed by powder X-ray diffraction (XRD) analysis, by using the Philips PW $3710 \mathrm{XRD}$ system which was operated at $40 \mathrm{KV}$ and $45 \mathrm{~mA}$, with a $\mathrm{CuK} \alpha(\lambda=1.54 \AA)$ radiation and a graphite monochromator. The composition of the fulgurites was determined by using a Philips X-ray fluorescence (XRF) machine at the National Geophysical Research Institute,
Hyderabad, India. In X-ray fluorescence method, typical uncertainty involved in oxide analyses was about $0.01 \mathrm{wt} \%$. One part of the sample was crushed into fine powder for analysis. The powdered sample was homogenized in spectroscopic grade $\operatorname{KBr}(1: 20)$ in an agate mortar and pressed into $3 \mathrm{~mm}$ pellets with a hand press. We tried to minimize the grinding time to avoid the deformation of the crystal structure, the ion exchange and the water absorption from atmosphere. The infrared spectra was acquired using Perkin-Elmer system 2000 FTIR spectrophotometer at Guwahati University, Guwahati, India, with helium-neon as the reference, at a resolution of $4 \mathrm{~cm}^{-1}$. The spectra were taken in the region $400-4000 \mathrm{~cm}^{-1}$. The room temperature was $30^{\circ} \mathrm{C}$ during the experiment.

\section{Results and discussion}

Sand fulgurites are usually created when lightning strikes the Earth and locally melts quartz sand, and the sand is instantly heated up to ultra high-temperatures (air temperatures may temporarily reach $10,000-30,000^{\circ}$ Celcius) 
and fulgurites can then form, tracing the path the lightning took, generally decreasing in diameter and sometimes branching as they descended. Fulgurites often take the form of tubes, sometimes exceeding $30 \mathrm{~mm}$ or more in diameter, and are known to exceed 8 meters in length (although this great length makes their recovery as a whole impossible as they are extremely fragile). The outer surfaces are often rough with adhering, unfused quartz sand grains. If they are tubular, the inner surfaces are usually smooth and glassy. Because of the rare occurrence, typical fulgurites cost from 50-150 US dollars. The XRF results show the major component of the sample to be $\mathrm{SiO}_{2}$. The results are compared with that of the previous work on fulgurites found elsewhere in similar geological settings (Frondel 1962). Table 1 shows the chemical composi-

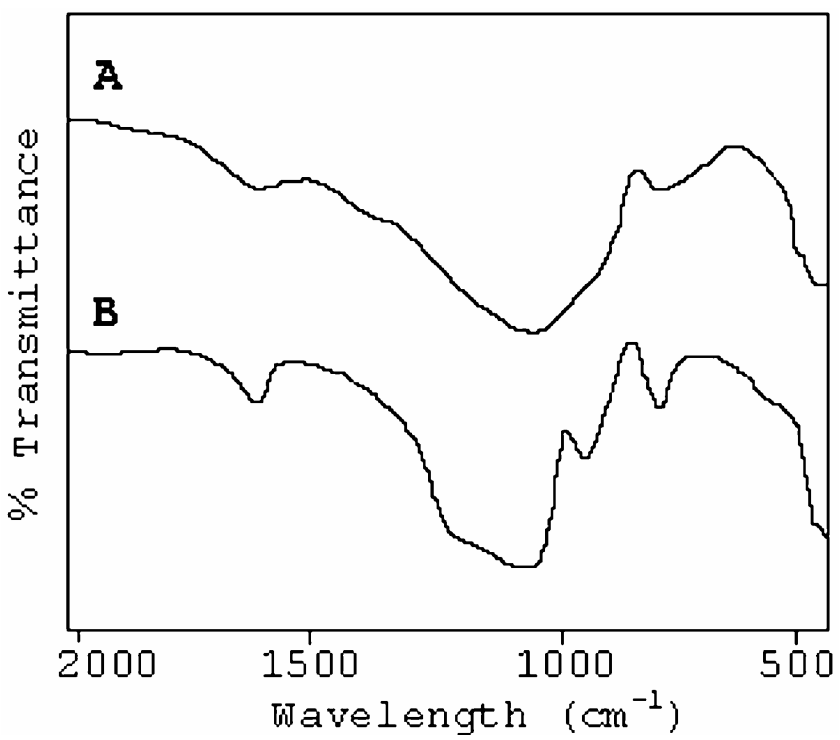

Figure 2. Comparison of FT-IR spectra of the natural fulgurites sample (A) and the spectra of the amorphous silica (B) (Ojima 2003) in the $20 \mu \mathrm{m}\left(500 \mathrm{~cm}^{-1}\right)$ and $10 \mu \mathrm{m}\left(1000 \mathrm{~cm}^{-1}\right)$ regions

Table 2. The observed absorption frequencies $\left(\mathrm{cm}^{-1}\right)$ of Fourier transform infrared spectra of the natural fulgurites and the assignments.

\begin{tabular}{ll}
\hline Wave number $\left(\mathrm{cm}^{-1}\right)$ & \multicolumn{1}{c}{ Assignments } \\
\hline 459 & $\mathrm{Si}-\mathrm{O}$ asymmetrical bending vibration \\
787 & $\mathrm{Si}-\mathrm{O}$ symmetrical stretching vibration \\
952 & $\mathrm{Si}-\mathrm{O}$ stretching vibration \\
1069 & $\mathrm{Si}-\mathrm{O}$ asymmetrical stretching vibration \\
1170 & $\mathrm{Si}-\mathrm{O}$ asymmetrical stretching vibration \\
$1392-1476$ & $\mathrm{CO}_{3}^{2-}$ stretching \\
$1508-1560$ & $\mathrm{CO}_{3}^{2-}$ symmetric stretch (13) \\
1635 & $\mathrm{OH}_{\text {bending vibration }}$ \\
$1684-1720$ & $\mathrm{CO}_{3}^{2-}$ symmetric stretch (13) \\
$2868-2969$ & $\mathrm{C}-\mathrm{H}$ stretching vibration \\
3452 & (organic contaminants) \\
\hline
\end{tabular}

tions of the natural fulgurites sample from Garuamukh and their comparison with earlier data on fulgurites produced by lightning. The absence of diffraction peaks in the broad pattern indicates that quartz is amorphous or glassy. The spectrum shows a slope of peak around $23^{\circ}$ corresponding to the amorphous matrix of $\mathrm{SiO}_{2}$. The overall pattern is that of amorphous silica. The sharp peaks observed in XRD (figure 1) are due to the presence of crystalline quartz as impurities.

The FTIR spectrum reveals a few absorption bands. The groups of bands in the region $400-700 \mathrm{~cm}^{-1}$ and 800 $1175 \mathrm{~cm}^{-1}$ are assigned as $20 \mu \mathrm{m}$ and $10 \mu \mathrm{m}$, respectively. In the $\mathrm{Si}-\mathrm{O}$ stretching vibration region $\left(800-1175 \mathrm{~cm}^{-1}\right)$, the bands at $787,952,1069,1170 \mathrm{~cm}^{-1}$ are identical to the bands at $800,958,1088 \mathrm{~cm}^{-1}$ due to amorphous silica (Ojama 2003). The $10 \mu \mathrm{m}$ and $20 \mu \mathrm{m}$ bands of Garuamukh fulgurites and the amorphous silica is shown in figure 2. It is seen that the characteristic frequencies slightly differ but the relative intensities vary in both silicates. Amorphous silica exhibited a relatively strong peak at $800 \mathrm{~cm}^{-1}$ and it can be distinguished from the band of crystalline silicate (Ojama 2003).

The structure of most $\mathrm{SiO}_{2}$ polymorphous, both crystalline and amorphous, is based on tetrahedral unit of silicon coordinated to four oxygen atoms. Amorphous silica is one of the polymorphous of silica and at high temperature it can easily transform from quartz. In the $\mathrm{Si}-\mathrm{O}-\mathrm{Si}$ bending vibration region $\left(400-700 \mathrm{~cm}^{-1}\right)$ of quartz, the band at $695 \mathrm{~cm}^{-1}$ is determinative whether it is crystalline or amorphous (Parthasarathy et al 2001). In the amorphous state this band will be missing. In the fulgurites sample, we did not get $695 \mathrm{~cm}^{-1}$ peak which indicates that the silica mineral in this sample is in amorphous form. The absorption band at $695 \mathrm{~cm}^{-1}$ is due to the vibrations in octahedral site symmetry and at $780 \mathrm{~cm}^{-1}$, it is due to the vibration in tetrahedral site symmetry (Schneider 1974; Parthasarathy et al 2001). The tetrahedral symmetry is stronger than that of octahedral symmetry. Therefore, for any structural change, the damage occurs first in octahedral then in tetrahedral symmetry. When the temperature

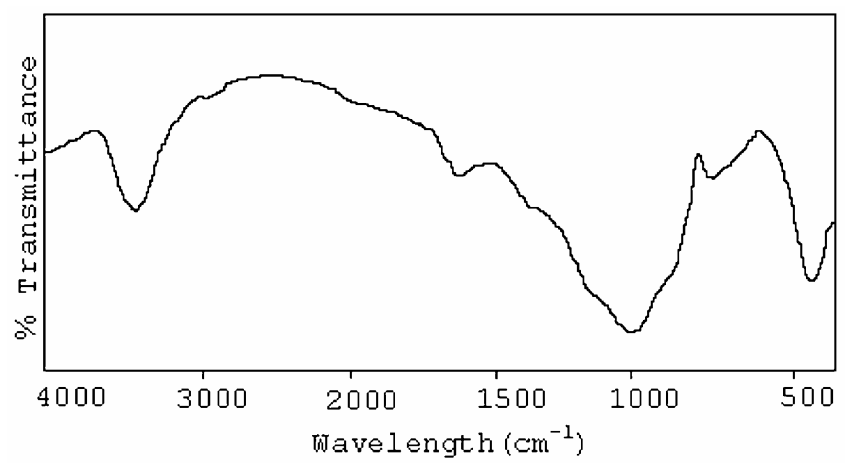

Figure 3. The IR spectra of the natural fulgurites sample from Garuamukh, Assam (India) in between 400 and $4000 \mathrm{~cm}^{-1}$. 
generally quenched so rapidly to $600-700^{\circ} \mathrm{C}$, the $\mathrm{SiO}_{4}$ tetrahedral could not be ordered to crystalline state and were preserved in an amorphous silicate phase.

The transmission FTIR spectrum of the fulgurites sample is shown in figure 2. The frequencies of IR bands and the possible assignments are listed in table 2 . In the $20 \mu \mathrm{m}$ region only one band is found at $459 \mathrm{~cm}^{-1}$ corresponding to the $\mathrm{Si}-\mathrm{O}$ asymmetrical mode of vibration. The carbonate structure contains isolated $\mathrm{CO}_{3}^{2-}$ group with a doubly degenerate symmetric stretch (13) at the region 1508$1560 \mathrm{~cm}^{-1}$ (Parthasarathy et al 2002). The IR bands at $1684-1720 \mathrm{~cm}^{-1}$ could be assigned to the bending vibration of $\mathrm{H}-\mathrm{O}-\mathrm{H}$ dissolved volatile species. The bands at $2868-2969 \mathrm{~cm}^{-1}$ could be assigned to stretching vibration of $\mathrm{C}-\mathrm{H}$ band which may be introduced during sample handling or some hydrocarbon present in the soil contaminant. The bands at $1392-1476 \mathrm{~cm}^{-1}$ is due to the Na-nonbridging oxygen-carbonate ion stretching vibration $(\mathrm{Na}-$ $\mathrm{NBO}-\mathrm{CO}_{3}^{-}$) (King et al 2004). The speciation of water in silicate glass formed by rapid quenching from melt equilibrated at high temperature reflect the nature of the melt, so it is important to note that the molecular water and hydroxyl group coexist in rapidly quenched glass (Stopler 1982). The absorption bands at $3452 \mathrm{~cm}^{-1}$ and $1635 \mathrm{~cm}^{-1}$ arise due to adsorbed water molecule commonly observed in natural silica (Parthasarathy et al 2001).

\section{Conclusions}

The present investigation of the Assam fulgurites represents the first FTIR spectroscopic study on any Indian fulgurites till date. The characteristic features of amorphous silica with some other trace minerals were identified by FT-IR spectroscopic method. In the silica, structural change is due to the coordination change. The amorphous phase due to the effect of tetrahedron and octahedron can be observed in the infrared data. While this transformation occurs, the materials pass through intermediate state. The XRF results show the major component of the sample to be $\mathrm{SiO}_{2}$. The broad Bragg peaks observed in X-ray diffraction studies reveal that the sample could be nanocrystalline quartz. The temperature required for the formation of octahedral symmetry in glassy fulgurites is found to be much lower than that of crystalline samples. The present characterization study of fulgurites could be useful in understanding the short-range order in fulgurites produced by shock metamorphism.

\section{Acknowledgements}

We thank Directors of NGRI and IICT, for providing the analytical facilities. We also thank Prof. A J Choudhury, Gauhati University and N K Gogoi, NGRI, for useful discussions. One of us (GP) is thankful to ISRO, Department of Space, Government of India, for financial support under PLANEX program.

\section{References}

Carron M K and Lowman P D 1961 Nature 19040

Clocchiatti R 1990 Eur. J. Mineral. 2479

Essen E J and Fisher D C 1986 Science 234189

Frondel C 1962 in Dana's system of minerology, 'Fulgurite' Encyclopedia Britannica (New York: Wiley) p. 321

Jayakaran S C 1998 Curr. Sci. 75765

King P L, McMillan P F and Moore G M 2004 Infrared spectroscopy in geochemistry, exploration geochemistry and remote sensing (Canada: Mineralogical Association of Canada) p. 93 Ojima J 2003 J. Occup. Health 4594

Parthasarathy G, Kunwar A C and Srinivasan R 2001 Eur. J. Mineral. 13127

Parthasarathy G, Chetty T R K and Haggerty S E 2002 Am. Mineral. 871384

Schneider H 1974 Contrib. Miner. Petr. 43233

Sheffer A A, Dyar M D and Sklute E C 2006 Lunar and Planetary Science XXXVII 2009

Sponholz B 2004 Earth and Environmental Science 10273

Stopler E 1982 Contrib. Miner. Petr. 811

Yavuz N and Can M 1999 Metallwissen. Technik. 53607 